January 2017

\title{
Identifying Instructional Methods for Development of Clinical Reasoning in Entry-Level Occupational Therapy Education: A Mixed Methods Design
}

Whitney Henderson

Creighton University

Brenda Coppard

Creighton University

Yongyue Qi

Creighton University

Follow this and additional works at: https://encompass.eku.edu/jote

Part of the Occupational Therapy Commons

\section{Recommended Citation}

Henderson, W., Coppard, B., \& Qi, Y. (2017). Identifying Instructional Methods for Development of Clinical Reasoning in EntryLevel Occupational Therapy Education: A Mixed Methods Design. Journal of Occupational Therapy Education, 1 (2). https://doi.org/ $10.26681 /$ jote.2017.010201 


\title{
Identifying Instructional Methods for Development of Clinical Reasoning in Entry-Level Occupational Therapy Education: A Mixed Methods Design
}

\begin{abstract}
Occupational therapy education must teach using contemporary and evidence-based practices that yield graduates with clinical reasoning skills to successfully practice in dynamic and challenging environments. Researchers used a mixed-methods research design to identify the most frequently used and valued instructional methods for developing clinical reasoning with entry-level occupational therapy students. Researchers recruited full-time educators teaching in entry-level occupational therapy programs throughout the United States. Ninety-two occupational therapy educators completed the survey for the quantitative portion of the study. Subsequently, six occupational therapy educators participated in an interview for the qualitative portion of the study. Participants most frequently used laboratory experiences and least frequently used rotating chair discussion for developing clinical reasoning. Participants perceived experiential learning as the most valuable and rotating chair discussion as the least valuable instructional method for developing clinical reasoning. The three themes of the educator, the student, and the environment emerged from the qualitative data. Outcomes suggest occupational therapy educators must embrace the role of facilitator and continue to explore a variety of effective instructional methods. In order to achieve this role, occupational therapy educators need to engage in personal and professional development. Researchers provide additional strategies for developing the clinical reasoning skills required for successful occupational therapy practice.
\end{abstract}

\section{Keywords}

Clinical competence, occupational therapy students, teaching methods

\section{Creative Commons License (c) (1) (3)}

This work is licensed under a Creative Commons Attribution-Noncommercial-No Derivative Works 4.0 License.

\section{Acknowledgements}

The researchers thank the participants for their time to partake in this study; Dr. Vanessa Jewell, Ph.D., OTR/ L and Dr. Kathleen Flecky, OTD, OTR/L for guidance during the completion of this project; and the faculty at the University of Missouri-Columbia for feedback on the survey and on this manuscript. 


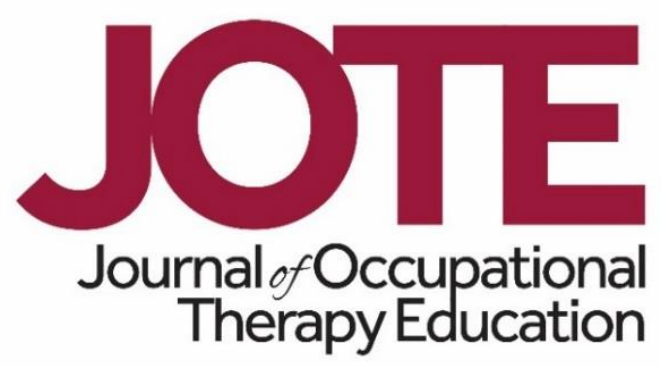

Volume 1, Issue 2

\begin{abstract}
Identifying Instructional Methods for Development of Clinical Reasoning in EntryLevel Occupational Therapy Education: A Mixed Methods Design
\end{abstract}

Whitney Henderson, MOT, OTR/L, Brenda Coppard, Ph.D., OTR/L, FAOTA, and

\author{
Yongyue Qi, M.S. \\ Creighton University \\ United States
}

\begin{abstract}
Occupational therapy education must teach using contemporary and evidence-based practices that yield graduates with clinical reasoning skills to successfully practice in dynamic and challenging environments. Researchers used a mixed-methods research design to identify the most frequently used and valued instructional methods for developing clinical reasoning with entry-level occupational therapy students.

Researchers recruited full-time educators teaching in entry-level occupational therapy programs throughout the United States. Ninety-two occupational therapy educators completed the survey for the quantitative portion of the study. Subsequently, six occupational therapy educators participated in an interview for the qualitative portion of the study. Participants most frequently used laboratory experiences and least frequently used rotating chair discussion for developing clinical reasoning. Participants perceived experiential learning as the most valuable and rotating chair discussion as the least valuable instructional method for developing clinical reasoning. The three themes of the educator, the student, and the environment emerged from the qualitative data.

Outcomes suggest occupational therapy educators must embrace the role of facilitator and continue to explore a variety of effective instructional methods. In order to achieve this role, occupational therapy educators need to engage in personal and professional development. Researchers provide additional strategies for developing the clinical reasoning skills required for successful occupational therapy practice.
\end{abstract}

\title{
INTRODUCTION
}

Occupational therapy education is accountable to higher education to meet educational outcomes and to society to produce competent practitioners (Gupta \& Bilics, 2014; Schaber, 2014). In the healthcare environment, there is pressure to hire professionals who can serve a variety of individuals with complex needs in various practice settings 
(Coker, 2010). Occupational therapists must use clinical reasoning to deliver clientcentered and occupation-based services that are grounded in theory and evidence to meet these complex needs (American Occupational Therapy Association [AOTA], 2015). Therefore, occupational therapy education must provide contemporary and evidence-based educational practices that yield graduates with the relevant skills for successful practice in dynamic and challenging environments (Burke \& Harvison, 2014; Coker, 2010; Furze et al., 2015; Gupta \& Bilics, 2014).

Similar to the need for evidence-based practice, it is essential that occupational therapy education is informed by evidence-based teaching to best prepare students for practice (Gupta \& Bilics, 2014). Experts recognize that clinical reasoning is an essential skill for practice (Furze et al., 2015; McCannon, Robertson, Caldwell, Juwah, \& Elfessi, 2004; Scaffa \& Wooster, 2004), and that occupational therapy education is initially responsible for the development and growth of this critical skill (Coker, 2010; Scaffa \& Smith, 2004). However, there is little evidence about which instructional methods are best for, or unique to, occupational therapy education (Hooper, King, Wood, Bilics, \& Gupta, 2013).

Researchers in occupational therapy education have investigated an assortment of instructional methods (Gupta \& Bilics, 2014; Hooper et al., 2013). Although such research has expanded the body of evidence, there appears to be a wide variety of instructional methods found in the literature. Therefore, no one instructional method for developing clinical reasoning has been heavily investigated, and current studies largely only examine a local learning environment (Gupta \& Bilics, 2014; Hooper et al., 2013). Because of this, occupational therapy education has not adequately identified the instructional methods used to best develop the clinical reasoning skills of students engaged in entry-level occupational therapy education.

\section{LITERATURE REVIEW}

\section{Clinical Reasoning}

Authors provide many definitions of clinical reasoning in occupational therapy. For this paper, we chose the definition used in the first clinical reasoning study (Mattingly, 1991). Clinical reasoning is a high level, cognitive thought process that integrates professional and acquired knowledge to deliver occupational therapy services in various contexts with clients with complex concerns (Mattingly, 1991). Mattingly (1991) reported that clinical reasoning in occupational therapy is not only articulating knowledge but is a skill that is translated "...through our hands and our eyes..." (p. 979). The development of clinical reasoning in occupational therapy follows a continuum of five stages and is a skill that is developed over time (Furze et al., 2015; Neistadt, 1996; Unsworth, 2001). The five stages include novice, advanced beginner, competent, proficient, and expert, with each stage marked by a variety of characteristics (Neistadt, 1996; Unsworth, 2001). Because years of clinical practice and continuing education are required to achieve or maintain the competent, proficient, and expert levels of clinical reasoning, it is unreasonable to expect occupational therapy students or entry-level practitioners to provide services at these stages (Neistadt, 1996). However, with an increase in complexity and pace of the healthcare environment, clinical reasoning will not only be 
expected but also required for entry-level practitioners to consistently perform at the novice and advanced beginner stages (AOTA, 2015).

\section{Teaching Clinical Reasoning}

Teaching clinical reasoning is vital to the preparation of occupational therapy students. While providing foundational knowledge is straight forward for educators in occupational therapy, teaching students the application of these concepts to the complex healthcare climate is challenging (Coker, 2010; Lysaght \& Bent, 2005; Scaffa \& Wooster, 2004). Educating students to use clinical reasoning to think like a therapist is difficult because of (a) the multitude of factors that contribute to this cognitive process, (b) a variety of definitions throughout the health professional education literature, (c) the diversity of student experiences, and (d) an ingrained way of thinking and acting in situations that is challenging for educators to articulate (Delany \& Golding, 2014; Furze et al., 2015; McCannon et al., 2004; Neistadt, 1996). Therefore, it is important for occupational therapy educators to understand which instructional methods are effective for the development of clinical reasoning (Gupta \& Bilics, 2014).

Educators tend to teach the way they learned occupational therapy. In a typical occupational therapy classroom, a lecture is followed by an active learning activity guided by the instructor (Schaber, 2014). The evidence indicates the use of lecture no longer adequately prepares students (Neistadt, 1999) because students are passive participants in the teaching-learning process (Knowles, 1980; Knowles, 1984; LoPresto \& Slater, 2016). Literature suggests a wide array of instructional methods as alternatives to lecture format, but does not define what educators do to adequately prepare students engaged in occupational therapy entry-level education. There is a need for faculty to appraise the instructional methods used to teach the art and science of the profession (Gupta \& Bilics, 2014; Schaber, 2014).

Clinical reasoning reflects the art and science of occupational therapy. Various types of clinical reasoning are well-documented in occupational therapy education (Neistadt, 1996), including narrative, procedural, interactive, pragmatic, ethical and scientific (Boyt Schell \& Schell, 2008). Neistadt (1996) reported occupational therapy educators are more effective when they explicitly tell students the type of clinical reasoning they are using in various classroom activities. This facilitates metacognition because students become aware of their cognitive thought processes (Akturk \& Sahin, 2011). In addition, in occupational therapy education literature, scholars have described instructional methods for teaching various types of clinical reasoning but have not yet investigated their effectiveness (Neistadt, 1996).

\section{Instructional Methods}

The American Occupational Therapy Association (2014) defines instructional methods as the "...specific strategies used to promote learning" (p. S83). Instructional methods include planning, organizing, executing, and assessing learning activities (Hooper et al., 2013). In order to develop clinical reasoning, educators in occupational therapy must be skilled in grading instructional methods, providing feedback, selecting appropriate media, and allowing opportunities for student decision-making (Lysaght \& Bent, 2005). 
Current literature suggests educators in occupational therapy use an eclectic array of instructional methods to facilitate the development of the clinical reasoning skills needed for entry-level practice (Coker, 2010; Hooper et al., 2013). Although in its infancy, occupational therapy educators are favoring the study of instructional methods in research (Gupta \& Bilics, 2014).

Although a variety of instructional methods are recognized in occupational therapy education literature, problem-based learning (PBL) appears to be the most prevalent instructional method for the development of clinical reasoning in the last two decades (Coker, 2010; Gupta \& Bilics, 2014; Hooper et al., 2013). Interestingly, following completion of a literature review on PBL and occupational therapy education, few articles about PBL were found that exist within the last five years. One of the primary reasons educators select $P B L$ as an instructional method is the belief that $P B L$ develops the clinical reasoning skills of occupational therapy students (Coker, 2010; McCannon et al., 2004). However, the effectiveness of PBL for the development of clinical reasoning in occupational therapy literature remains mixed (Coker, 2010; McCannon et al., 2004).

Another instructional method gaining increased attention in recent occupational therapy education literature is the use of experiential learning. Literature suggests experiential learning improves the preparation of students to meet the demands of entry-level practice (Coker, 2010). In a study completed by Knecht-Sabres (2013), data revealed each of the 36 student participants demonstrated advanced clinical reasoning skills on a researcher developed 10 -item questionnaire following an experiential learning opportunity. Similarly, Coker (2010) found a one-week experiential learning component improved occupational therapy students' scores on two clinical reasoning questionnaires. Although authors reported positive results in the previous studies, research on this instructional method in occupational therapy education remains limited.

Additional instructional methods mentioned in occupational therapy literature include debate, concept mapping, journaling, short videos, simulation labs, role-playing and games (AOTA, 2014; Hooper et al., 2013; Neistadt, 1996). Although several instructional methods are mentioned, few have been rigorously investigated in occupational therapy education literature. Other disciplines provide supporting evidence for instructional methods, such as PBL in medical education and simulation-based learning in nursing (Cant \& Cooper, 2017; Nelville, 2009). Educators in occupational therapy need to "...see more explicitly what they are doing in their instructional repertoire and practice" (Mitcham, 2014, p. 642). Before further investigation of the effectiveness of various instructional methods, the need remains to identify the frequently used and valued instructional methods for the development of clinical reasoning with occupational therapy students engaged in entry-level education. Once identified, researchers in occupational therapy education can begin to heavily investigate the effectiveness of these instructional methods on the development of the critical skills required for practice. The purpose of this study was to (1) identify instructional methods faculty are using to develop clinical reasoning in entry-level 
occupational therapy education and (2) determine what instructional methods faculty report as valuable for the development of clinical reasoning.

\section{METHODS}

\section{Research Design}

This research study utilized a sequential mixed methods design to explore the instructional methods faculty used and valued to develop clinical reasoning with occupational therapy students. Researchers used the sequential direction from a quantitative design to a qualitative design. This direction allowed researchers to test the research question through quantitative methods before gaining a deeper understanding through qualitative approaches (DePoy \& Gitlin, 2016). For the quantitative portion of this study, researchers used a non-experimental, exploratory survey design. Researchers used a general inductive approach to collect data through the use of interviews for the qualitative portion of the study. This methodology allowed findings to emerge from the raw data (Thomas, 2006). The Institutional Review Board at Creighton University approved this study and granted a waiver of informed consent. In the quantitative portion, participants consented through completion of the survey. In the qualitative portion, the participants provided verbal consent at the start of the interview.

\section{Participants and Sampling}

Researchers recruited occupational therapy faculty at entry-level programs in the United States in two phases: surveys (quantitative) and interviews (qualitative). For the quantitative portion of the study, researchers used a nonprobability convenience sampling method to recruit participants with a recruitment email containing an informational letter and link to complete the online survey. Researchers obtained email addresses from publically available program webpages, requested program directors forward information about the survey to appropriate faculty, requested emails be sent to the Education Special Interest Section listserv, and sent emails to faculty members previously met through networking opportunities. It is possible that a faculty member received two invitations. Researchers used the quantitative survey to recruit participants for the qualitative interviews. In the qualitative portion of the study, researchers recruited participants with a nonprobability, maximum variation purposive sampling method. Participants provided contact information during the survey if willing to participate in an interview. Of these participants, researchers selected six participants with a wide variety of characteristics, such as a range of years of experience in academia and various academic positions and ranks, to gain a greater perspective of instructional method use and value for developing clinical reasoning. Researchers sent an additional information letter and recruitment email to these participants for enrollment in this portion of the study.

Inclusion criteria for each component of the study included (1) full-time faculty, working as $75 \%$ full-time equivalent with any academic rank or track, (2) faculty teaching in an entry-level occupational therapy program in the United States, (3) ability to comprehend English, and (4) having access to technology to complete the online survey. Exclusion 
criteria included (1) part-time faculty or adjunct faculty, (2) fieldwork educators, and (3) faculty in an occupational therapy assistant program.

\section{Instruments}

For the quantitative portion of the study, the researchers developed a survey to determine the frequency of instructional method use and participants' perception of the value of instructional methods for developing clinical reasoning. Researchers used the literature to develop this survey and performed a pilot test with a group of four occupational therapy faculty for additional feedback. To ensure diversity of feedback, we selected faculty with varied backgrounds. Faculty had between two and 14 years of teaching experience (mean $=9$ years). Their education backgrounds varied as well (i.e. two with a Ph.D. and two with an OTD; three had teaching experiences at a public institution and one had experience at a private institution; they taught a variety of degree levels). The survey consisted of a 19-item questionnaire using a 6-point Likert ordinal scale. Scores ranged from 1 (unsure) to 6 (always) for frequency of use and 1 (unsure) to 6 (very valuable) for perceived value of the instructional method for developing clinical reasoning. The survey also collected demographic data and included a definition of clinical reasoning, service learning, and experiential learning. Because the researchers planned to collect qualitative data through the use of interviews, we elected to exclude a text box on the survey for additional instructional methods. Researchers administered the survey via a secure online survey (Qualtrics), and the survey was approximately 15 to 20 minutes in length. An excerpt from the survey is included in Figure 1. The 27 instructional methods included in the survey are listed in Table 1.

In any course designed to develop or improve clinical reasoning skills, how frequently do you use the following instructional methods?

\begin{tabular}{|c|c|c|c|c|c|c|}
\hline & $\begin{array}{l}\text { Always } \\
(100 \%)\end{array}$ & $\begin{array}{l}\text { Frequently } \\
\text { (75\%) }\end{array}$ & $\begin{array}{l}\text { Occasionally } \\
(50 \%)\end{array}$ & Rarely (25\%) & Never (0\%) & $\begin{array}{l}\text { Unsure of } \\
\text { that method }\end{array}$ \\
\hline $\begin{array}{l}\text { Lecture and/or PowerPoint } \\
\text { Presentation }\end{array}$ & 0 & 0 & 0 & 0 & 0 & 0 \\
\hline $\begin{array}{l}\text { General Laboratory/Hands } \\
\text { On Experiences }\end{array}$ & O & 0 & 0 & 0 & $\mathrm{O}$ & $\mathrm{O}$ \\
\hline General Discussion & 0 & 0 & 0 & 0 & 0 & 0 \\
\hline $\begin{array}{l}\text { Case-Based Instruction or } \\
\text { Problem-Based Learning }\end{array}$ & 0 & 0 & 0 & 0 & 0 & O \\
\hline
\end{tabular}

Figure 1. Sample survey questions. 
Table 1

Instructional Methods Included in the Survey

1. Lecture and/or Power 10. Videos (YouTube, ICE 19. Rotating Chair

Point Presentation video learning, videos from practice, podcast, Discussion etc.)

2. General

11. Tutorials

20. Socratic Questioning

Laboratory/Hands On

Experiences

3. General Discussion

12. Web-Based Learning

21. Discussion Board (Virtual Tours, Online Lectures, etc.)

4. Case-Based Instruction or Problem-Based Learning
13. Students-Teaching- Students or Peer Teaching

5. Experiential Learning

14. Jigsaw Classroom

23. Role Playing

6. Service Learning

15. 1-3-6 Technique

24. Reflective Journaling

7. Field Experience, Field Trip, Field Study

16. Turn and Talk or ThinkPair-Share

8. Classroom as Clinic or "Living Lab"

17. Brainstorming

9. Simulation (ComputerBased, Objective Structured Clinical Examination, etc.)

22. Games

25. Concept Mapping

26. Expert Panel or Guest Speakers

18. Debate

27. Independent Study

From the quantitative data and literature, two of the researchers developed a semistructured interview to increase the depth and breadth of information about use and value of the instructional methods and clinical reasoning. The interview consisted of seven open-ended questions with opportunities to supplement with further questions as needed. The primary researcher completed the interview via phone, and each interview was approximately 45 minutes in length. The interview questions are included in Figure 2. 
1. How do you select the instructional methods you use to develop clinical reasoning?

2. Describe how you consider how the instructional method facilitates the development of clinical reasoning.

3. Which instructional methods do you believe are the most beneficial to the development of clinical reasoning? Why? The least beneficial? Why?

4. Describe how you tell students the type of clinical reasoning they are developing or using in the selected classroom activity.

5. The most frequently used instructional methods identified from the survey were laboratory experience, discussion, problem-based or case-based learning, experiential learning, videos, and lecture. Do you believe these instructional methods are effective in developing clinical reasoning? Why or why not?

6. The most valuable instructional methods identified from the survey were experiential learning, problem-based or case-based learning, laboratory experience, service learning, and classroom as clinic / "living lab." Do you believe these instructional methods have anything in common? Do you believe these methods facilitate clinical reasoning?

Figure 2. Interview questions.

\section{Procedures}

Following recruitment and consent procedures, participants in the quantitative portion of the study completed the secure online survey using Qualtrics. Researchers sent one reminder email to participants and collected quantitative data for four weeks. In this portion of the study, researchers collected minimal identifying information to maintain anonymity and stored the data on the secure online survey and downloaded to a secure account. Twenty-four participants provided contact information for participation in the qualitative portion of the study. Researchers purposefully selected six participants to include a variety of characteristics. Following recruitment and consent procedures for the qualitative portion of the study, participants completed an interview via phone in a private office. Researchers collected data for two weeks and recorded and transcribed each interview. Researchers stored the recorded interviews and contact information in a secure location. Although minimal identifying information was obtained, researchers reviewed and de-identified each transcribed interview as needed. 


\section{Data Analysis}

For the quantitative portion of the study, researchers used descriptive statistics to analyze data from the survey, including frequency distribution and measures of central tendency to summarize demographic data (Depoy \& Gitlin, 2016). Additionally, researchers used rank and frequency distribution to explore instructional method use and the value of instructional methods. Rank was used to identify the five most frequently and least frequently used and the five most valuable and least valuable instructional methods. We selected five instructional methods because there was a break in the data that separated these choices.

For the qualitative portion of the study, two of the researchers used thematic analysis to analyze data generated from the interviews. After transcription, the primary researcher read the interviews several times and manually completed coding procedures. Researchers began with initial coding to label the data (Braun \& Clarke, 2006; Thomas, 2006). The primary researcher completed this stage, and the secondary researcher reviewed and provided feedback during the peer debriefing process. Based on these suggestions, the primary researcher revised the initial coding. Following this stage, the primary researcher reviewed the initial codes to determine connections and develop categories (Braun \& Clarke, 2006). Again, the secondary researcher reviewed this stage and provided additional feedback to begin to identify potential themes. Finally, researchers collaborated to determine relationships to identify themes and subthemes (Braun \& Clarke, 2006). The primary investigator recorded the themes, subthemes, and interview statements in a secure document.

To improve the trustworthiness, researchers used methodological triangulation to compare the qualitative and quantitative data and to gain a deeper understanding of instructional method use and value for developing clinical reasoning. In addition, researchers completed the member checking process by sending each transcribed interview to participants to validate and revise the content (Curtin \& Fossey, 2007). Researchers also completed an audit trail to document each step of this portion of the study.

\section{RESULTS}

\section{Quantitative Data}

Ninety-two occupational therapy educators completed the survey. Eighty-five females and six males participated in the quantitative portion of this study. One individual did not disclose gender status. Fifty-three participants (57.6\%) had 0-10 years of experience, 23 participants (25\%) had 11-20 years of experience, and 16 participants (17.4\%) had more than 21 years of experience in occupational therapy education. Seventy-two participants (78.3\%) worked at the rank of an Assistant or Associate Professor. Additionally, the participants in the quantitative portion of the study reported spending an average of $54.7 \%$ of their job duties performing teaching activities. 
Instructional methods used. In order to determine the frequently used instructional methods for developing clinical reasoning, researchers combined the 'always' and 'frequently' ratings. Of the 27 instructional methods included in the survey, laboratory experience was the most common method $(n=78 ; 84.8 \%)$, while rotating chair (the current student speaking chooses the next person to speak) was the least common method $(n=5 ; 5.4 \%)$. The five most and least frequently used instructional methods are listed in Table 2. Many participants were unfamiliar with the instructional methods of jigsaw classroom and 1-3-6 teaching methods as indicated by selecting 'unsure' $(n=50$; $54.3 \%$ and $n=70 ; 82.6 \%$, respectively).

Table 2

Most and Least Frequently Used Instructional Methods for Developing Clinical Reasoning

Most Frequently Used $(n=92) \quad$ Least Frequently Used $(n=92)$

1. Laboratory Experiences $(\mathrm{n}=78$; $84.8 \%)$

2. General Discussion ( $n=76 ; 82.5 \%)$

3. Problem-Based Cases or Case-Based Learning $(n=70 ; 76.1 \%)$

4. Experiential Learning $(n=59 ; 64.1 \%)$

5. Videos $(n=58 ; 63.0 \%)$
1. Rotating Chair $(n=5 ; 5.4 \%)$

2. Concept Mapping ( $n=10 ; 10.7 \%)$

3. Tutorials $(n=11 ; 12.0 \%)$

4. Games $(n=12 ; 13.0 \%)$

5. Discussion Board $(n=16 ; 17.4 \%) \&$ Socratic Questioning $(n=16 ; 17.4 \%)$

Participants provided information about specific coursework and experiences in their respective occupational therapy curriculum. Specifically, $93 \%$ of participants $(n=86)$ reported including experiential learning, and $48 \%$ of participants $(n=44)$ reported using an in-house teaching clinic in the occupational therapy curriculum. Additionally, $48 \%$ of participants $(n=44)$ stated there was a course dedicated to problem-based learning, while $57 \%$ of participants $(n=52)$ had a course specific to teaching clinical reasoning in the occupational therapy curriculum.

Value of instructional methods. To determine the value of instructional methods for developing clinical reasoning, researchers combined the 'very valuable' and 'valuable' ratings. Of the 27 instructional methods included in the survey, experiential learning was perceived to be the most valuable method $(n=89 ; 96.7 \%)$; while rotating chair was the least valuable method $(n=12 ; 13.0 \%)$. The five most and least valuable instructional methods are listed in Table 3. 
Table 3

Most and Least Valuable Instructional Methods for Developing Clinical Reasoning Most Valuable $(n=92) \quad$ Least Valuable $(n=92)$

1. Experiential Learning $(n=89 ; 96.7 \%)$ 1. Rotating Chair $(n=12 ; 13.0 \%)$

2. Problem-Based Cases or Case-Based 2. Lecture $(n=20 ; 21.7 \%)$ Learning $(n=82 ; 89.1 \%)$

3. Laboratory Experiences $(n=79$; $85.9 \%)$

3. Discussion Board $(n=20 ; 21.7 \%)$

4. Service Learning $(n=72 ; 78.3 \%)$

4. Tutorials $(n=24 ; 26.1 \%)$

5. Classroom as Clinic or "Living Lab" $(\mathrm{n}=70 ; 76.1 \%)$

5. Web-Based Learning $(n=24 ; 26.1 \%)$

Learning experiences in occupational therapy programs. Additionally, researchers analyzed two other survey items. On the survey, $82 \%$ of participants reported 'always' $(n=22)$ or 'frequently' $(n=53)$ purposefully selecting the type of instructional methods when attempting to develop clinical reasoning with occupational therapy students (Figure 3).

\section{HOW OFTEN DO YOU PURPOSEFULLY SELECT THE TYPE OF INSTRUCTIONAL METHOD WHEN ATTEMPTING TO DEVELOP CLINICAL REASONING WITH ENTRY-LEVEL OCCUPATIONAL THERAPY STUDENTS}

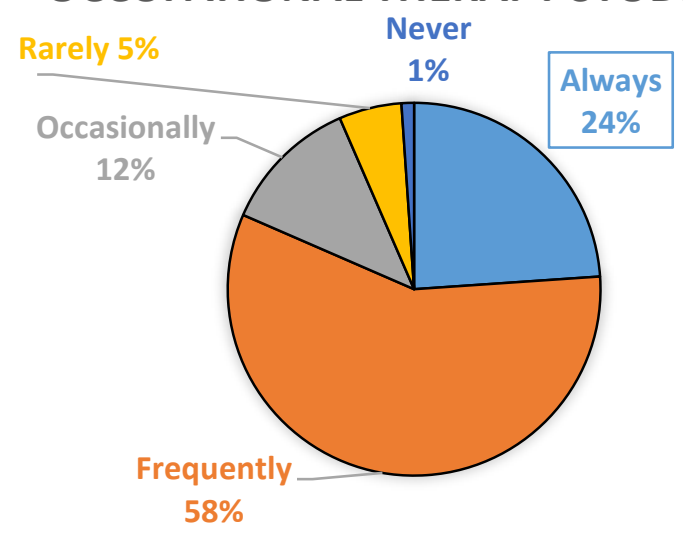

Figure 3. How often educators purposefully select instructional methods. 
When asked 'how frequently do you tell students the type of clinical reasoning they are using in classroom activities', only $40 \%$ of participants $(n=37)$ reported frequently informing students (Figure 4).

\section{HOW FREQUENTLY DO YOU TELL STUDENTS THE TYPE OF CLINICAL REASONING THEY ARE USING IN CLASSROOM ACTIVITIES?}

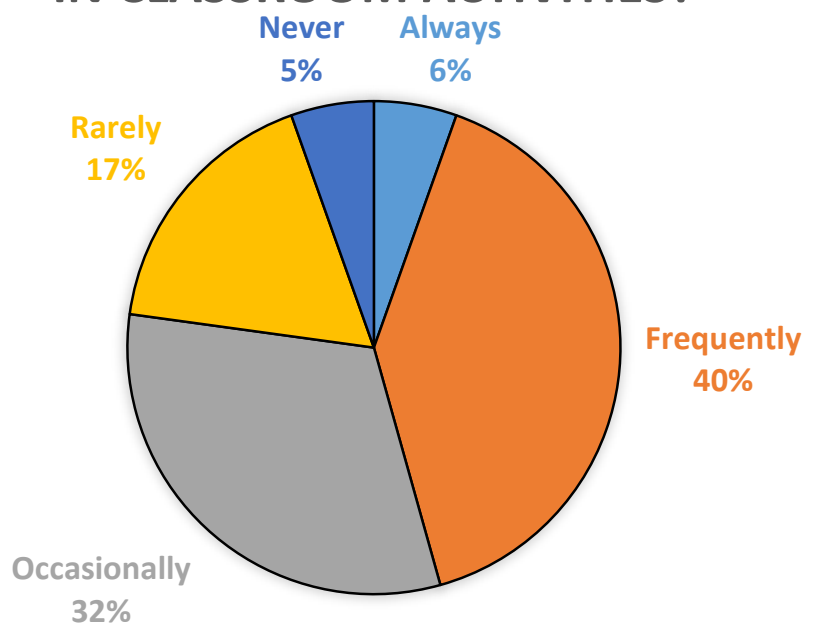

Figure 4. How often occupational therapy educators tell students the type of clinical reasoning being used in classroom activities.

\section{Qualitative Data}

Six occupational therapy educators participated in a phone interview. All six participants were female. Two participants had 0-10 years of experience in occupational therapy education, while four participants had 11-20 years of experience in occupational therapy education. Four participants worked at the rank of an Assistant or Associate Professor, one participant worked at the rank of Professor, and one participant served as the director of an occupational therapy program. These participants reported spending an average of $58.3 \%$ of their job duties performing teaching activities with a range from 40 to $70 \%$ of the time.

Three themes and eight subthemes emerged from analysis of the interviews, including the educator, the student, and the environment.

Theme one: The educator. In theme one, the educator used a similar process for educating students as that of an occupational therapist involved in the occupational therapy process. Participants' responses revealed the three subthemes of (1) grading instructional methods, (2) modeling, and (3) influencing implementation.

Grading of instructional methods. Similar to how occupational therapists grade interventions, educators grade instructional methods to fit the needs of their students. 
One participant reported the need for the instructional method "to have this balance between some degree of structure, but some degree of flexibility." In regards to modifying the instructional method, one participant stated, "I learned from student engagement and the lively time in the classroom when things [instructional methods] are working and I also learned when things [instructional methods] aren't working." Finally, one participant described modifying a class as the semester progressed because "every class is different and if I feel like they are not getting something... I'll alter the upcoming labs."

Modeling. A majority of the participants discussed the need to model and promote clinical reasoning. Examples of modeling included (1) "I'll demonstrate to them this is how you would interview someone, so I would interview one of them and show them that, and then I have them do that for me"; (2) "In the group class, I role model warm up activities and then I role model how to process through that activity"; and (3) "I would have students come with me and I would basically model, this is how I would do it, but then I would have them kind of jump in and do things and give them feedback as we are going."

Influences on implementation. Participants discussed several positive and negative influences when implementing instructional methods to encourage clinical reasoning. Positive influences for selecting instructional methods included (1) "modeling other faculty in the department", (2) reflection through "self-assessment and course assessment", (3) keeping "track of the evidence that supports different types of pedagogy", and (4) doing "a lot of continuing education." Participants identified time and effort as the primary negative influences on changing instructional methods. One participant reported, "it takes a heck of a lot of time to generate an appropriate sim [simulation] experience and to train people and an incredible amount of organization." Similarly, one participant stated, "it takes time and effort to change your teaching style, and I think we just kind of get used to standing up there in front of the classroom and lecturing, and maybe that is all as a student we were exposed to."

Theme two: The student. In theme two, the student is comparable to the client engaged in the occupational therapy process. Participants' responses revealed the three subthemes of (1) matching instructional methods with the student's developmental process, (2) needing opportunities, and (3) engaging in meaningful learning experiences.

Match instructional methods with the student's developmental process. In regards to a course that occurs during the second semester of didactic coursework, one participant reported, "I don't even bring patients into labs...I don't bring them into labs because it's just too early." Some participants reported infrequently using experiential learning because "again it is so early in their learning." Similarly, another participant stated, "we start them off with highly structured learning experiences" and "that it [instructional methods] has to be sequenced properly throughout the curriculum so they are ready for it." 
Need opportunities. The participants identified the need for students to have a variety of opportunities. One example included, "actually letting them [students] have a go at it first so that they have the opportunity to try to make those connections." The same participant provided learning activities so that students also had a chance to "problem solve" prior to class. One participant identified that the students need the opportunities for "a lot of feedback" and for "creativity" during educational experiences.

Meaningful learning experiences. Participants provided benefits and examples of meaningful learning activities. Several participants reported that students have to understand how they will use the information. For example, one participant stated, "they need to see the direct impact of how that meets their goals for becoming an occupational therapist." Another participant reported, "you'll see adult learners need to see the direct benefit to anything that they're going to spend their time on."

Theme 3: The environment. Similar to occupational therapy practice, the environment plays a critical role during in the educational experience. Participants' responses revealed the two subthemes of (1) characteristics of a conducive learning environment and (2) active learning experiences.

Characteristics of a conducive learning environment. A majority of the participants articulated that the learning environment should be safe, non-threatening, and fun. One participant stated, "I do think case-based learning is a nice way for them to learn clinical reasoning because it's in a safe, non-threatening environment", while another participant reported, "but I think in the classroom setting, it's nice to create an environment where they feel like they can come up with things and make mistakes." Additionally, a participant said, "this generation in particular wants a little bit of entertainment and a little bit of fun, so if you can make learning fun and at the same time you give them feedback right, then I think that is good."

Active learning experiences. Each participant believed instructional methods that incorporated active learning were most beneficial to developing clinical reasoning. Additionally, several participants provided examples of active learning. One participant stated, "I try to keep them awake and incorporate active things as much as possible." Another participant agreed that good instructional methods "require the students to be active, co-constructors of their knowledge." Similarly, one participant reported, "we try to incorporate as much experiential learning through database analysis, through reading, and processing case scenarios, doing classroom discussions, doing what we call think, pair, share."

\section{DISCUSSION}

In this study we identified the frequency of use and perceived value of instructional methods for developing clinical reasoning with occupational therapy students. In addition, we examined if occupational therapy educators explicitly indicate to students the types of clinical reasoning they are using during classroom activities. A majority of our findings were expected and consistent with previous research findings. 


\section{Quantitative Data}

There were only six of the 27 instructional methods that more than half of the participants frequently used for developing clinical reasoning. This finding suggests that occupational therapy educators use a limited repertoire of instructional methods compared to the evidence-based teaching practices available throughout professional education literature. If students are expected to use clinical reasoning in complex healthcare environments during entry-level practice (Burke \& Harvison, 2014; Gupta \& Bilics, 2014), occupational therapy educators must expand their view of teaching to explore new and different instructional methods to adequately prepare students (FoordMay, 2006; Graffam, 2007). Although the literature suggests that educators favor investigation of instructional methods in occupational therapy education research (Gupta \& Bilics, 2014; Hooper et al., 2013), a wide variety of these approaches do not appear to be translating to educators' teaching methods or strategies based on our findings. Perhaps occupational therapy educators need to embrace the role of a facilitator who employs active learning methods (Foord-May, 2006; Graffam, 2007). Just as occupational therapy practitioners use evidence-based interventions, occupational therapy educators must continue to further develop and incorporate a variety of evidence-based teaching practices to foster active learning and clinical reasoning.

Researchers found that occupational therapy faculty recognized the value of instructional methods, but did not always incorporate valuable methods into their teaching practices. One potential reason for the mismatch between value and use is a lack of faculty development early in their teaching career. In higher education, there is a belief that educators are not prepared to teach and have limited knowledge of what constitutes effective teaching (Amundsen \& Wilson, 2012). Also, the literature indicates that pedagogical knowledge is the most difficult to develop and is not knowledge that is inherent by holding an advanced professional degree (Kreber \& Cranton, 2000). Several higher education institutions are recognizing these issues and are implementing a variety of methods to develop teaching practices (Amundsen \& Wilson, 2012). However, to be effective, the transformative learning theory suggests there is a need for these initiatives to promote reflection on teaching (professional) and reflection on inner beliefs and assumptions (personal) for continuous improvement in teaching (Hooper, 2007). Therefore, occupational therapy educators ought to engage in professional development, as well as professional and personal reflection, to better integrate valuable instructional methods into teaching practices.

Findings suggest that a majority of occupational therapy educators do not inform students about the type of clinical reasoning they are using in classroom activities. This finding is unexpected as literature supports this interaction between the student and educator for cognitive growth and critical thinking. Neistadt (1996) suggested occupational therapy educators are more effective when they tell students how an assignment should develop clinical reasoning. Similar to the need for practitioners to improve occupational therapy practice through reflection on their thinking process (Neistadt, 1996), Schön's (1983) reflective practitioner model supports this form of metacognition in education. Knowing-in-action is a task (clinical reasoning) that is demonstrated but not articulated. By describing clinical reasoning during an active 
learning activity, the information is converted to knowledge-in-action, which becomes a part of a student's memory. Reflection-in-action is conscious thought about our thinking and actions. Drawing from social-cognitive and constructivist literature, there is a need for occupational therapy educators to both facilitate reflection-in-action and discuss what is happening to assist students to construct new knowledge and to think about the reasoning that leads to certain actions (Bruning, Schraw, \& Norby, 2011).

\section{Qualitative Data}

The themes that emerged from the qualitative data are well supported by the educational literature. The constructivist theory and adult learning theories support the subthemes of grading instructional methods and matching methods with students' developmental process. From the constructivist viewpoint, cognitive changes occur in the zone of proximal development. The zone of proximal development is the difference between what the learner can do with independence and what the learner can do with the assistance from the educator (del Rio, 2007). Therefore, occupational therapy educators ought to strive to select or grade instructional methods that best fit the students' developmental zone. Similarly, adult learning theory suggests students develop a readiness to learn when they see a need to learn so they can advance to the next stage of development. Therefore, educators must appropriately sequence and integrate learning experiences across a course and curriculum to facilitate students' growth (Knowles, 1980).

The constructivist and adult learning theories also provide support for the subthemes of the value of meaningful and active learning experiences in occupational therapy education. The constructivist learning theory emphasizes that learners be active in constructing their own knowledge and to be responsible for assigning meaning during the learning process (Loyens, Rikers, \& Schmidt, 2009). Similar to the constructivist theory, the adult learning theory reports the speed and direction of growth are positively impacted when learners are placed in an active role. Also, educators must be clear about the relevance of the learning experience (meaningful) to the learners' lives because motivation to learn increases when students understand the need to learn and how learning will help them achieve a particular goal (Knowles, 1980). Therefore, to develop critical thinking and cognitive growth, occupational therapy educators must select meaningful and active instructional methods in which students make sense of the content.

Lastly, the social cognitive learning theory supports the subtheme of the importance of modeling for developing clinical reasoning. Educators who model a task demonstrate how particular skills are performed; modeling also provides motivation for student learning (Bandura, 1997). Additionally, the literature supports the subtheme of the educator providing a safe learning environment for learning. The environment is conducive to learning when students feel safe for exploration (Bandura, 1997), feel a sense of trust and mutual respect, and experience a fun and gratifying activity (Knowles, 1980; Knowles, 1984). Therefore, we suggest occupational therapy educators continue to find ways to model various concepts and to continue to create a positive atmosphere for student learning. 


\section{Limitations}

The researchers recognize limitations in this study. Because of a small convenience sample, this study has limited generalizability. Additionally, the use of convenience sampling potentially created a bias as only participants interested in the topic could have elected to participate in the study. Although researchers piloted the survey, we did not establish reliability and validity. Due to the nature of a survey in the quantitative portion of the study, participants might have misinterpreted the survey questions, and researchers were unable to confirm the accuracy of the participants' responses. In addition, it is possible that a faculty member received two invitations to participate in the study. For the qualitative portion of the study, each interview was completed via telephone; some participants may have preferred face-to-face interaction to build rapport. Although researchers completed actions to increase the credibility of the qualitative findings, the results in this portion of the study remain subject to bias.

\section{Implications for Future Research}

We suggest areas for further investigation. First, researchers in occupational therapy education could further explore the effectiveness of an instructional method for developing clinical reasoning across multiple institutions. Similarly, educators can develop studies to compare instructional methods for determining which methods are more effective for developing clinical reasoning. During these potential investigations, researchers need to use a standardized tool to measure clinical reasoning (e.g. SelfAssessment of Clinical Reflection and Reasoning by Royeen, Mu, Barrett, and Luebben, 2001). Secondly, a study examining the types of faculty development for implementation of evidence-based teaching practices into occupational therapy education would be beneficial. Lastly, researchers can investigate the types of metacognitive strategies that are effective to prepare students for reflection in practice so they can be responsive to the individualized needs of the people they serve.

\section{Conclusion}

This research study provided information about faculty members' frequency of use and perceived value of instructional methods for developing clinical reasoning in occupational therapy education. Occupational therapy educators must continue to explore a variety of instructional methods and embrace the role of a facilitator. To achieve the aforementioned activities, there is a need for occupational therapy educators to engage in various forms of professional development. Additionally, the results suggest educators incorporate metacognitive strategies, form a safe environment, model the profession's concepts, and select meaningful and active instructional methods (see Table 1) to develop the clinical reasoning required for success in entry-level occupational therapy practice.

\section{References}

Akturk, A. O., \& Sahin, I. (2011). Literature review on metacognition and its measurement. Procedia Social and Behavioral Sciences, 15, 3731-3736. http://dx.doi.org/10.1016/j.sbspro.2011.04.364 
American Occupational Therapy Association [AOTA]. (2014). Research agendaOccupational therapy education research agenda. American Journal of Occupational Therapy, 68, S83-S86. http://dx.doi.org/10.5014/ajot.2014.685S06

American Occupational Therapy Association [AOTA]. (2015). Philosophy of occupational therapy education. American Journal of Occupational Therapy, 69(Suppl. 3), 6913410053. http://dx.doi.org/10.5014/ajot.2015.696S17

Amundsen, C., \& Wilson, M. (2012). Are we asking the right questions? A conceptual review of the educational development literature in higher education. Review of Educational Research, 82(1), 90-126. doi: 10.3102/0034654312438409

Bandura, A. (1997). Self-efficacy: The exercise of control. New York, NY: Freeman.

Boyt Schell, B. A., \& Schell, J. W. (2008). Clinical and professional reasoning in occupational therapy. Baltimore, MD: Lippincott Williams \& Wilkins.

Braun, V., \& Clarke, V. (2006). Using thematic analysis in psychology. Qualitative Research in Psychology, 3(2), 71-101. http://dx.doi.org/10.1191/1478088706qp063oa

Bruning, R. H., Schraw, G. J., \& Norby, M. M. (2011). Cognitive psychology and instruction ( $5^{\text {th }}$ ed.). Boston, MA: Pearson.

Burke, J. P., \& Harvison, N. (2014). From the Desk of the Guest Editors-A systematic focus on occupational therapy education. American Journal of Occupational Therapy, 68, S1-S2. http://dx.doi.org/10.5014/ajot.2014.685S07

Cant, R. P., \& Cooper, S. J. (2017). Use of simulation-based learning in undergraduate nurse education: An umbrella systematic review. Nurse Education Today, 49, 63-71. http://dx.doi.org/10.1016/j.nedt.2016.11.015

Coker, P. (2010). Effects of an experiential learning program on the clinical reasoning and critical thinking skills of occupational therapy students. Journal of Allied Health, 39(4), 280-286.

Curtin, M., \& Fossey, E. (2007). Appraising the trustworthiness of qualitative studies: Guidelines for occupational therapists. Australian Occupational Therapy Journal, 54, 88-94. http://dx.doi.org/10.1111/j.1440-1630.2007.00661.x

del Rio, P. (2007). Inside and outside the zone of proximal development: An ecofunctional reading of Vygotsky. In H. Daniels, M. Cole, \& J. Werstch (Eds.). The Cambridge companion to Vygotsky (pp. 276-302). New York, NY: Cambridge University Press.

Delany, C., \& Golding, C. (2014). Teaching clinical reasoning by making thinking visible: An action research project with allied health clinical educators. BMC Medical Education, 14(1). http://dx.doi.org/10.1186/1472-6920-14-20

DePoy, E., \& Gitlin, L. N. (2016). Introduction to research: Understanding and applying multiple strategies (5th ed.). St. Louis, MO: Elsevier.

Foord-May, L. (2006). A faculty's experience in changing instructional methods in a professional physical therapist education program. Physical Therapy, 86(2), 223235. https://doi.org/10.1093/ptj/86.2.223

Furze, J., Black, L., Hoffman, J., Barr, J. B., Cochran, T. M., \& Jensen, G. M. (2015). Exploration of students' clinical reasoning development in professional physical therapy education. Journal of Physical Therapy Education, 29(3), 22-33. 
Graffam, B. (2007). Active learning in medical education: Strategies for beginning implementation. Medical Teacher, 29, 38-42. http://dx.doi.org/10.1080/01421590601176398

Gupta, J., \& Bilics, A. (2014). Brief Report-Scholarship and research in occupational therapy education. American Journal of Occupational Therapy, 68, S87-S92. http://dx.doi.org/10.5014/ajot.2014.012880

Hooper, B. (2007). Shortening the distance between the "I" and the "it": A transformation approach to improving teaching. Occupational Therapy in Health Care, 21(1/2), 199-215. http://dx.doi.org/10.1080/J003v21n01_15

Hooper, B., King, R., Wood, W., Bilics, A., \& Gupta, J. (2013). An international systematic mapping review of educational approaches and teaching methods in occupational therapy. British Journal of Occupational Therapy, 76(1), 9-22. http://dx.doi.org/10.4276/030803313X13576469254612

Knecht-Sabres, L. J. (2013). Experiential learning in occupational therapy: Can it enhance readiness for clinical practice. Journal of Experiential Education, 36(1), 22-36. http://dx.doi.org/10.1177/1053825913481584

Knowles, M. S. (1980). The modern practice of adult education: From pedagogy to andragogy. Chicago, IL: Association Press Follett Publishing Company.

Knowles, M. S. (1984). Andragogy in action: Applying modern principles of adult learning. San Francisco, CA: Jossey-Bass Publishers.

Kreber, C., \& Cranton, P. A. (2000). Exploring the scholarship of teaching. The Journal of Higher Education, 71(4), 476-495. http://dx.doi.org/10.1080/00221546.2000.11778846

LoPresto, M. C., \& Slater, T. F. (2016). A new comparison of active learning strategies to traditional lectures for teaching college astronomy. Journal of Astronomy \& Earth Sciences Education, 3(1), 59-76.

Loyens, S. M., Rikers, R. M., \& Schmidt, G. H. (2009). Students' conceptions of constructivist learning in different programme years and different learning environments. British Journal of Educational Psychology, 79, 501-514. doi: $10.1348 / 000709908 \times 378117$

Lysaght, R., \& Bent, M. (2005). A comparative analysis of case presentation modalities used in clinical reasoning coursework in occupational therapy. American Journal of Occupational Therapy, 59, 314-324. doi:10.5014/ajot.59.3.314

Mattingly, C. (1991). What is clinical reasoning? American Journal of Occupational Therapy, 45(11), 979-986. doi:10.5014/ajot.45.11.979

McCannon, R., Robertson, D., Caldwell, J., Juwah, C., \& Elfessi, A. (2004). Comparison of clinical reasoning skills in occupational therapy students in USA and Scotland. Occupational Therapy International, 11(3), 160-176. doi: 10.1002/oti.204

Mitcham, M. D. (2014). Education as engine (Eleanor Clarke Slagle Lecture). American Journal of Occupational Therapy, 68, 636-648. http://dx.doi.org/10.5014/ajot.2014.686001

Neistadt, M. E. (1996). Teaching strategies for the development of clinical reasoning. American Journal of Occupational Therapy, 50(8), 676-684. doi:10.5014/ajot.50.8.676 
Neistadt, M. E. (1999). Educational interpretation of "cooperative learning as an approach to pedagogy". American Journal of Occupational Therapy, 53(1), 4143. doi:10.5014/ajot.53.1.41

Nelville, A. J. (2009). Problem-based learning and medical education forty years on. Med Princ Prac, 18, 1-9. http://dx.doi.org/10.1159/000163038

Royeen, C., Mu, K., Barrett, L., \& Luebben, A. (2001). Pilot investigation: Evaluation of a clinical reflection and reasoning before and after workshop intervention. In P. Crist (Ed.), Innovations in Occupational Therapy Education (pp. 107-114). Bethesda, MD: American Occupational Therapy Association.

Scaffa, M. E., \& Smith, T. M. (2004). Effects of level II fieldwork on clinical reasoning in occupational therapy. Occupational Therapy in Health Care, 18(1-2), 31-38. http://dx.doi.org/10.1080/J003v18n01_04

Scaffa, M. E., \& Wooster, D. M. (2004). Brief Report-Effects of problem-based learning on clinical reasoning in occupational therapy. American Journal of Occupational Therapy, 58, 333-336. doi:10.5014/ajot.58.3.333

Schaber, P. (2014). Conference Proceedings-Keynote address: Searching for and identifying signature pedagogies in occupational therapy education. American Journal of Occupational Therapy, 68, S40-S44. http://dx.doi.org/10.5014/ajot.2014.685S08

Schön, D. A. (1983). The reflective practitioner: How professionals think in action. New York, NY: Basic Books, Inc.

Thomas, D. R. (2006). A general inductive approach for analyzing qualitative evaluation data. American Journal of Evaluation, 27(2), 237-246. http://dx.doi.org/10.1177/1098214005283748

Unsworth, C. A. (2001). The clinical reasoning of novice and expert occupational therapists. Scandinavian Journal of Occupational Therapy, 8, 163-173. http://dx.doi.org/10.1080/110381201317166522

Unsworth, C. A. (2005). Using a head-mounted video camera to explore current conceptualizations of clinical reasoning in occupational therapy. American Journal of Occupational Therapy, 59, 31-40. doi:10.5014/ajot.59.1.31 